\title{
PONOROGO: MENGGALI JATI DIRI UNTUK MEMBANGUN HARMONI
}

\author{
Saifuddin Alif Nurdianto \\ Prodi Pendidikan Sejarah Fakultas Keguruan dan Ilmu Pendidikan \\ Program Pascasarjana Universitas Sebelas Maret \\ Jalan Ir. Sutami No.36A, Jebres, Surakarta \\ email: saifuddinalif2@gmail.com
}

\section{PONOROGO: EXPLORING IDENTITY TO CREATE HARMONY}

\author{
Naskah masuk: 2 - 04 - 2018 \\ Revisi akhir: 25 - 05 - 2018 \\ Disetujui terbit: 4 - 06 - 2018
}

\begin{abstract}
Ponorogo was previously called Wengker. Ponorogo is one of the Indonesia's cultural icons with its Reog and is famous as the city of santri (students of Islamicboarding schools), has a dark past. The name of Ponorogo was coined by Bathara Katong in 1496 as a manifestation of his preachings. It was also the sign of the end of the old order, which was full of negative stigma, and the beginning of the better new order. Using philosophical and ethnosemantic approaches, this qualitative research examined the underlying reasons why Bathara Katong changed the name Wengker into Ponorogo. The new name contains philosophical meaning, that is, Ponorogo endeavours to become dynamic and creative civil society which upholds the values of civilization.
\end{abstract}

Keywords: Wengker, Ponorogo, Bathara Katong, civil society

\begin{abstract}
Abstrak
Ponorogo yang saat ini menjadi salah satu ikon budaya Indonesia dengan kesenian Reyog, dan terkenal sebagai kota santri ternyata memiliki masa lalu yang kelam. Pada masa lalu Ponorogo memiliki sebutan Wengker yang dikenal sebagai daerah yang penuh dengan stigma negatif. Nama Ponorogo sendiri baru muncul pada tahun 1496 yang dikenalkan oleh Bathara Katong, sebagai manifestasi dari dakwah yang telah dilakukan dan simbol dari berakhirnya tatanan lama yang penuh stigma negatif, menjadi tatanan baru yang lebih baik. Penelitian kualitatif dengan pendekatan filosofis dan etnosemantik digunakan untuk mengkaji perubahan nama dari Wengker menjadi Ponorogo yang dilakukan oleh Bathara Katong pada tahun 1496, yang memiliki makna filosofis berupa ikhtiar untuk menjadikan masyarakat Ponorogo sebagai masyarakat yang madani, yaitu masyarakat yang dinamis, penuh kreativitas, dan menjunjung tinggi nilai-nilai peradaban.
\end{abstract}

Kata kunci: Wengker, Ponorogo, Bathara Katong, masyarakat madani

\section{PENDAHULUAN}

Ponorogo adalah salah satu kabupaten di Jawa Timur yang terkenal sebagai kota kelahiran kesenian reyog. Selain itu, Ponorogo memiliki sejarah panjang dalam kehidupan sosial, ekonomi, dan keagamaan masyarakat Jawa. Meskipun demikian, banyak yang belum tahu bahwa kota 
yang juga dikenal sebagai kota santri ini dahulu memiliki sejarah yang kurang menyenangkan. Kondisi tersebut tercermin dari nama Wengker yang memiliki konotasi negatif untuk menyebut wilayah Ponorogo sebelum tahun 1496. Wengker adalah kerata basa1 "wewengkon kang angker", yaitu suatu wilayah yang menakutkan.

Pada masa kuno, Kerajaan Wengker memiliki rivalitas yang ketat dengan Kerajaan Kediri dalam perebutan hegemoni di sekitar Gunung Wilis. Raja Panuda dari Wengker bahkan disebut-sebut sebagai musuh terkuat Airlangga ketika membangun dinastinya di Kediri. Dalam prosesnya, Wengker kemudian dapat dikalahkan oleh serangan Airlangga pada tahun 953 Saka (1031 M). ${ }^{2}$ Pada masa selanjutnya, nama Wengker banyak muncul dalam kitab Nagarakrtagama sebagai sebagai salah satu kerajaan bawahan Majapahit. Tidak dijelaskan secara rinci bagaimana peran Kerajaan Wengker ketika itu, tetapi dari cerita di dalam Nagarakrtagama terlihat bahwa Raja Wengker memiliki peran yang cukup menonjol, yang menunjukkan bahwa Wengker memiliki posisi strategis dalam konstelasi politik Majapahit. ${ }^{3}$

Memasuki masa penyebaran Islam di Jawa, Wengker juga tidak lepas dari proses islamisasi. Lembu Kanigoro adalah tokoh utama dalam proses islamisasi di Wengker. Dengan membawa misi dakwah, Lembu Kanigoro mencoba untuk memperkenalkan Islam dengan cara yang damai, mengingat mayoritas masyarakat di Wengker masih memeluk agama Hindu, Budha, Kapitayan, dan beberapa ajaran animisme dan dinamisme. ${ }^{4}$ Salah satu kompromi antara Islam dengan agamaagama tersebut, khususnya agama Hindu, Lembu
Kanigoro mengubah namanya menjadi Bathara Katong, sehingga dia tampil sebagai seorang utusan Dewa yang akan membawa perlindungan kepada masyarakat Wengker. ${ }^{5}$ Puncak dari islamisasi adalah ketika Bathara Katong mengganti nama Wengker yang memiliki konotasi negatif menjadi Ponorogo pada tahun 1496.

Konsep penamaan suatu tempat merupakan paradigma sosiokultural yang terdapat dalam suatu masyarakat, sebagai bentuk realisasi dari konsep sistem tanda dalam bahasa, yang kehadirannya tidak dapat dipisahkan dari aspek sosial-budaya yang melatarbelakanginya. ${ }^{6}$ Jadi, akan selalu ada keterkaitan antara nama tempat dengan keadaaan sosial-budaya dari masyarakat daerah tersebut. Konsep ini pula yang terjadi di Ponorogo, diiringi dengan reformasi moral, pergantian nama dari Wengker menjadi Ponorogo merupakan sebuah sistem tanda dari manifestasi dakwah yang telah dilakukan Bathara Katong. Ponorogo merupakan sebuah simbol dari berakhirnya tatanan lama yang penuh stigma negatif, menjadi tatanan baru yang lebih baik.

Perubahan ini ternyata membawa dampak positif dan sesuai dengan apa yang diharapkan oleh para pendiri Kota Ponorogo. Ponorogo berkembang menjadi salah satu pusat penyebaran agama Islam di Jawa. Salah satu puncak dari perkembangan Ponorogo sebagai pusat penyebaran Islam adalah munculnya pesantren pertama di Jawa, yaitu Pesantren Gebang Tinatar (Pesantren Tegalsari) tahun 1742. Semenjak saat itulah Ponorogo dikenal juga sebagai kota santri, karena banyaknya santri dan pesantren yang tersebar di kota ini. Pada masa selanjutnya, ketika pamor Pesantren Tegalsari

1 Kerata basa bisa juga disebut dengan istilah jarwa dhosok. Jarwa berarti memperjelas dan dhosok berarti mendorong, jadi secara harfiah dapat dipahami sebagai mempejelas dengan mendorong. Artinya, sebuah kata didorong sampai batas-batas makna melalui permainan kata-kata dengan penggunaan serenteng sinonim. Pamela Allen, "Reading Matters: An Examination of Plurality of Meaning in Indonesia Fiction 1980-1995", alih bahasa: Bakdi Soemanto, Membaca, dan Membaca Lagi: [Re]interpretasi Fiksi Indonesia, 1980-1995, (Magelang: Indonesia Tera, 2004$)$, hlm. 117.

2 Kisah ini termuat dalam prasasti Pucangan atau Calcutta Stone yang dibuat pada masa pemerintahan Airlangga. Lihat Agus Santoso, Arjunawiwaha, (Cianjur: Wiraraja Press, 2014), hlm. 94.

3 Supratikno Rahardjo, Peradaban Jawa: Dinamika Pranata Politik, Agama, dan Ekonomi Jawa Kuno (Depok: Komunitas Bambu, 2002), hlm. 509.

4 Ahmad Choirul Rofiq, "Patriotisme Masyarakat Ponorogo Menurut Babad Ponorogo", dalam Dialogia, Vol. 14, No. 1, 2016 , hlm. 150.

5 Muhaji Fikriono, Puncak Makrifat Jawa: Pengembaraan Batin Ki Ageng Suryomentaram (Jakarta: Noura Books, 2012), hlm. 50

6 Alip Sugianto, "Pola Nama Desa di Kabupaten Ponorogo pada Era Adipati Raden Batoro Katong (Sebuah Tinjauan Etnolinguistik)", dalam Humaniora, Vol. 10, Ed. 1, 2017, hlm. 36. 
mulai memudar akhir abad-19, aktivitas dakwah di Ponorogo secara cepat dilanjutkan oleh keturunan ulama Pesantren Tegalsari yang mendirikan Pondok Modern Darussalam Gontor pada tahun 1926.

Tulisan ini akan mengulas asal-usul Kota Ponorogo, yang dikaji secara deskriptif kualitatif dengan pendekatan filosofis dan etnosemantik. Asal-usul Ponorogo menarik untuk dikaji karena Ponorogo merupakan salah satu ikon dari budaya Indonesia dengan kesenian Reyog Ponorogo. Selain itu, Ponorogo juga merupakan salah satu kota yang memiliki banyak pesantren, sehingga dikenal juga dengan kota santri. ${ }^{7}$ Fakta lain yang belum banyak diketahui adalah, masa lalu Ponorogo ternyata tidak berbanding lurus dengan kenyataan yang ada pada masa sekarang. Pada masa lalu Ponorogo dikenal sebagai daerah yang penuh dengan stigma negatif. Perubahan dari daerah "kotor" menjadi kota yang religius seperti sekarang menjadi tema yang menarik untuk dikaji lebih lanjut.

\section{MENCARI MAKNA KATA "PONOROGO"}

\section{A. Sejarah Singkat Kota Ponorogo}

Ponorogo adalah daerah yang memiliki luas $1.371,78 \mathrm{~km}^{2}$, dan diapit oleh tiga gunung, yaitu Gunung Wilis, Gunung Lawu, dan Pegunungan Seribu. Sebelum Bathara Katong memperkenalkan nama Ponorogo pada tahun 1496, daerah ini dikenal dengan sebutan Wengker. Wengker adalah kerata basa "wewengkon kang angker", yaitu suatu wilayah yang menakutkan. Selain itu, Wengker juga dikenal dengan sebutan Bantarangin, yaitu tempat yang memiliki banyak angin. ${ }^{8}$
Sebutan "wewengkon kang angker" mengisyaratkan bahwa Wengker bukanlah tempat yang ramah bagi masyarakat yang baru mengenalnya. Hal ini sesuai dengan cerita rakyat yang berkembang di wilayah Ponorogo, bahwa pada masa lalu wilayah di antara Gunung Wilis dan Lawu merupakan sarang para bandit, di samping Kerajaan Wengker juga dikenal sering melakukan pemberontakan kepada Kerajaan Kediri yang dipimpin oleh Airlangga. Peristiwa pemberontakan ini diabadikan di prasasti Pucangan yang berangka tahun 963 Saka atau 1041 M. Dalam prasasti tersebut disebutkan bahwa Airlangga berhasil menumpas pemberontakan Haji Wengker pada tahun 953 Saka (1031 M), tetapi Haji Wengker berhasil melarikan diri. Dalam pelariannya, Haji Wengker kembali mencoba menghimpun kekuatan untuk melakukan pemberontakan lanjutan. Pemberontakan kembali dilakukan oleh Haji Wengker pada tahun 959 Saka (1037 M), yang lagi-lagi dapat ditumpas oleh Airlangga, dan berakhir dengan ditangkapnya Haji Wengker di Kapang. ${ }^{9}$

Citra negatif Wengker tidak lepas dari topografi wilayahnya yang cukup terpencil. Mendel menjelaskan dalam teorinya, bahwa aktualisasi ciri dan sikap seorang individu selalu dipengaruhi oleh faktor fisik (misalnya, makanan, udara, topografi) dan non fisik (misalnya, lingkungan sosial). ${ }^{10}$ Merujuk kepada teori Mendel, dapat dilihat bahwa salah satu sebab munculnya Wengker sebagai daerah yang kurang ramah adalah karena faktor fisik, yaitu wilayahnya yang diapit oleh tiga buah gunung, Gunung Wilis di timur, Pegunungan Seribu di selatan, dan Gunung Lawu di sebelah barat. Kondisi geografis semacam ini menyebabkan wilayah Wengker tidak begitu diminati untuk dijadikan pusat pemukiman karena sulit untuk

7. Data terakhir yang didapat dari Pangkalan Data Pondok Pesantren (PDPP) Kementerian Agama (Kemenag) RI, di Ponorogo ada 91 pondok pesantren. www.pbsb.ditpdpontren.kemenag.go.id, diakses pada Senin 19 Maret 2018.

8. Nuril Hidayati, "Kontestasi Politik Budaya antara Wengker dan Kadiri: Fragmentasi Genealogi Kesenian Jaranan", Prosiding Filsafat Islam: Historisitas dan Aktualisasi (Peran dan Kontribusi Filsafat Islam bagi Bangsa), Vol. 1, 2014, hlm. 182. 162-193.

9. J.J. Ras, "Maatschappij en Letterkunde op Java", alih bahasa: Achdiati Ikram, Masyarakat dan Kesustraan di Jawa (Jakarta: Pustaka Obor, 2014), hlm. 163-164.

10. Conny Semiawan dan Th.I. Immanuel Setiawan, dan Yufiarti, Panorama Filsafat Ilmu: Landasan Perkembangan Ilmu Sepanjang Zaman (Bandung: Teraju, 2005), hlm. 44 
dijangkau oleh daerah luar. Maka tidak heran apabila Wengker kemudian dijadikan sarang para penjahat yang kerap mempraktikkan ajaran-ajaran mistik. Dari keadaan sosiologis masyarakat seperti itu kemudian muncul warok, sebagai ikon "jagoan" dari Wengker. ${ }^{11}$

Pada masa selanjutnya, masa akhir HinduBudha, tidak banyak penjelasan tentang daerah Wengker. Catatan di kitab Nagarakrtagama hanya menjelaskan bahwa Wengker merupakan salah satu kerajaan bawahan Majapahit dengan otonomi yang cukup besar. ${ }^{12}$ Catatan ini memberikan isyarat bahwa Wengker memiliki peran strategis dalam konstelasi politik di Majapahit, tetapi tidak banyak yang bisa dibicarakan terkait apa dan bagaimana peran Wengker tersebut.

Citra negatif Wengker perlahan mulai berubah sejak masa persebaran Islam di Jawa abad ke-15. Proses islamisasi yang dilakukan oleh Bathara Katong di Wengker pada akhir abad ke-15 membawa dampak positif. Masyarakat Wengker secara bertahap mulai masuk agama Islam dan meninggalkan praktik-praktik mistik yang selama ini dilakukan. Sebagai manifestasi dari perubahan masyarakat, pada tahun 1418 Saka (1496 M) Bathara Katong mengubah nama Wengker menjadi Ponorogo. ${ }^{13}$

\section{B. Asal-Usul Nama Ponorogo}

Pergantian nama daerah bukanlah sesuatu yang begitu saja terjadi. Ada banyak keterkaitan antara penamaan suatu daerah dengan kondisi masyarakat di kawasan itu, baik dari secara sosiologis, antropologis, budaya, ataupun faktorfaktor yang lain. Sapir-Worf menjelaskan dalam teori relativitas linguistiknya bahwa ada keterkaitan antara bahasa, budaya, dan pikiran manusia. Orang berbicara dengan cara yang berbeda karena mereka berpikir dengan cara yang berbeda. Mereka berpikir dengan cara yang berbeda karena bahasa mereka menawarkan cara mengungkapkan (makna) dunia di sekitar mereka dengan cara yang berbeda pula. Lebih lanjut, Sapir-Worf menjelaskan bahwa struktur bahasa yang yang digunakan secara terus menerus akan mempengaruhi cara seseorang berpikir dan berperilaku. ${ }^{14}$ Merujuk teori ini, dapat dilihat bahwa pergantian nama dari Wengker ke Ponorogo merupakan refleksi dari bahasa, budaya, pikiran, dan pandangan dunia dari masyarakat setempat. Mengingat Bathara Katong adalah tokoh utama dari berdirinya kota Ponorogo, maka hampir dapat dipastikan bahwa Bathara Katong sendirilah yang memiliki peran sentral dalam pemberian nama Ponorogo.

Asal-usul dari pemberian nama Ponorogo memiliki beberapa versi. Hal ini tidaklah mengherankan karena memang tidak ada catatan sezaman yang menjelaskan asal-usul penamaannya, mengingat kuatnya tradisi tutur dibandingkan tradisi tulis dalam masyarakat Jawa. Asal-usul nama Ponorogo hanya hanya dapat ditemukan melalui catatan-catatan tersier dan cerita lisan yang disampaikan secara turun temurun, yang sangat mungkin terdistorsi ketika disampaikan dari satu orang ke orang yang lain. Meskipun demikian, tidak bisa dipungkiri bahwa penamaan Ponorogo merupakan sebuah refleksi dari kondisi sosial-budaya masyarakat Ponorogo sendiri, yang mungkin tidak ditemui di tempat lain.

Setidaknya ada tiga versi tentang asalusul penamaan Ponorogo. Versi pertama adalah dari Babad Ponorogo yang menjelaskan bahwa Ponorogo berasal dari kata pramana dan raga.

11. Warok adalah sebutan untuk tokoh masyarakat dari Ponorogo yang dianggap sakti, mempunyai kemampuan supranatural dan kelebihan dalam olah kanuragan. Lihat Khoirurrosyidin, "Dinamika Peran Warok dalam Politik Di Ponorogo", Humanity, Vol. 9, No. 2, 2014, hlm. 26. Setelah islamisasi, warok kemudian diarahkan kepada seseorang yang selalu menghindarkan diri dari dosa, merujuk kepada kata wara' dalam bahasa Arab. Lihat M. Irfan Riyadi, Anwar Mujahidin, Muh.Tasrif, "Conflict and Harmony between Islam and Local Culture in Reyog Ponorogo Art Preservation”, El-Harakah, Vol. 18, No. 2, 2016, hlm.159

12. Slamet Muljana, Menuju Puncak Kemegahan (Sejarah Kerajaan Majapahit) (Yogyakarta: LKiS, 2005$),$ hlm. 91.

13. Angka tahun ini merujuk kepada pelantikan Bathara Katong sebagai Adipati Ponorogo yang ditandai dengan adanya prasasti berupa sepasang batu gilang yang terdapat di depan gapura kompleks pemakaman Bathara Katong. Prasasti ini memiliki candrasangkala 4 dengan pahatan berwujud manusia, pohon, burung garuda, dan gajah yang melambangkan angka 1418 tahun Saka atau 1496 M. Lihat Muhammad Zamzam Fauzanafi, Reog Ponorogo: Menari di antara Dominasi dan Keragaman (Yogyakarta: Kepel Press, 2005), hlm. 47.

14. Alo Liliweri, Makna Budaya dalam Komunikasi Antarbudaya (Yogyakarta: LKiS, 2002), hlm.152. 
"Pramana iku manunggale sumbering cahaya saka srengenge rembulan lan bumi kan mahanani nyoroti sakabehing urip kang gumelar. Telung prakara iku diarani Trimurti, manjinge ana badaning manungsa jadi tri purusa. Tripurusa narik sari-arining badan wadhag, dadi mani. Mani lanang lawan wadon kumpul sinab dan karsaning Gusti bisa dadi wija dadi, dadi manungsa. Dadi pramana lawan raga iku ora isa pisah, kajaba yen wis mati. Pramana lawan raga ibarat kaya madu lan legina. Dene pana iku tegese tembung: wia mengerti marang sakabehing kahanan. Wis menegrti temenan. Raga itu tegese awak." ${ }^{\prime 5}$

Artinya:

"Pramana itu bersatunya sumber cahaya dari matahari, bulan, dan bumi yang menyoroti seluruh yang hidup. Tiga perkara itu dinamai Trimurti, apabila berada dalam tubuh manusia disebut Tripurusa. Tripurusa menarik sari dari tubuh, menjadi air mani. Mani laki-laki dan wanita berkumpul, dengan izin Tuhan menjadi manusia. Jadi pramana dan raga itu tidak bisa dipisahkan, kecuali jika sudah mati. Pramana dan raga seperti madu dengan manisnya. Sedangkan pana itu berarti telah mengetahui segala pengetahuan. Raga itu adalah badan."

Dari istilah ini, dapat dilihat bahwa penamaan Ponorogo adalah suatu harapan agar masyarakat Ponorogo memiliki fisik yang kuat dengan didukung ketetapan hati, sebagai hasil dari olah batin yang mantap. Olah batin ini dilakukan dengan penuh kesadaran jiwa dan spiritualitas yang tinggi, dengan menyandarkan diri kepada Tuhan penguasa alam.

Versi kedua berasal dari cerita rakyat yang menjelaskan bahwa Ponorogo berasal dari kata pana dan raga. Pana memiliki arti pintar dan raga yang berarti badan. Dilihat dari sisi ini, pemberian nama Ponorogo mengisyaratkan sebuah harapan agar masyarakat Ponorogo memiliki fisik yang kuat dengan diimbangi kemampuan intelektual yang baik, karena akal dan fisik adalah dua hal yang saling berkaitan secara dialektis. Fisik yang kuat memang penting, tetapi tanpa diimbangi dengan kemampuan intelektual yang baik, maka fisik tersebut tidak akan banyak memberikan manfaat. Sebaliknya, kemampuan intelektual yang baik tanpa diimbangi dengan fisik yang prima juga tidak ada artinya, karena kemampuan intelektual seseorang hanya akan dapat diaplikasikan dengan baik apabila dia juga memiliki fisik yang prima.

Versi ketiga dari penamaan Ponorogo berkaitan dengan legenda masyarakat setempat yang sarat dengan unsur mistis. Diceritakan bahwa Bathara Katong mengalami banyak rintangan dalam upaya islamisasi di Ponorogo. Salah satu rintangan terbesar adalah tentangan dari Ki Ageng Kutu yang menolak untuk masuk Islam disertai pemberontakan kepada Bathara Katong. Dalam posisi seperti itu, Bathara Katong terpaksa melawan Ki Ageng Kutu. Singkat kata Ki Ageng Kutu berhasil dikalahkan, namun jasadnya tidak pernah ditemukan. Banyak masyarakat yang menganggap Ki Ageng Kutu telah moksa. ${ }^{16}$ Bathara Katong yang telah mengalahkan Ki Ageng Kutu ini kemudian berniat untuk mencari nama baru bagi Wengker. Dalam proses pencarian nama tersebut, datanglah bisikan gaib dari Begawan misterius yang bernama Ki Prana. Ki Prana sendiri diyakini sebagai penjelmaan dari Ki Ageng Kutu yang sebelumnya dianggap telah moksa. Dari sosok Ki Prana inilah kemudian muncul istilah Pranaraga, yang dalam perjalanannya kemudian menjadi Ponorogo. Versi ketiga masuk dalam salah satu yang dipertimbangkan karena banyak catatancatatan kolonial yang menyebut daerah Ponorogo dengan istilah Pranaraga atau Pronorogo.

15. Perwowijoyo, Babad Ponorogo, (Surabaya: Nirbita, 1978), hlm. 27. Kebenaran dari Babad Ponorogo inipun belum bisa dipastikan, karena baru ditulis oleh Poerwowijoyo tahun 1978.

16. Ian Douglas Wilson, "Reog Ponorogo Spirituality, Sexuality, and Power in a Javanese Performance Tradition", Intersections: Gender and Sexuality in Asia and the Pacific, Issue 2, 1999, http://intersections.anu.edu.au/issue2/Warok.html. Moksa adalah kebebasan hidup yang kekal dan abadi. Bebas dari semua ikatan benda-benda duniawi serta bersatunya Atman (percikan kecil dari Brahman yang berada di dalam setiap makhluk hidup) dan Brahman (Tuhan). Dalam kepercayaan agama Hindu, orang yang mencapai moksa akan terbebas dari hukum Karma Phala dan Punarbawa, yaitu penjelmaan yang berulang-ulang. Lihat HM. Nasruddin Anshoriy, Neo Patriotisme: Etika Kekuasaan dalam Kebudayaan Jawa (Yogyakarta: LKiS, 2008), hlm. 59. 


\section{Ponorogo: Menggali Jati Diri untuk Membangun Harmoni}

Terlepas dari segala perbedaan tentang asal-usul pemberian nama Ponorogo, tidak bisa dipungkiri bahwa nama itu muncul sebagai hasil dari ikhtiar Bathara Katong dan para pengikutnya untuk mengubah masyarakat Wengker menjadi masyarakat yang lebih beradab. Keberadaban yang diharapkan dari masyarakat Ponorogo adalah kekuatan yang harus selalu dimiliki, luar dan dalam, lahir dan batin, jiwa dan raga. Kekuatan lahir dan batin perlu dimiliki oleh setiap insan, karena kombinasi dari kedua kekuatan inilah yang menyebabkan datangnya pertolongan dan perlindungan dari arah yang tidak disangka-sangka, yaitu dari Tuhan semesta alam.

Dari istilah Ponorogo, Bathara Katong seperti hendak menyampaikan bahwa di dalam raga seseorang, tersimpan sebuah rahasia besar yang berada di dalam batinnya. Batin seseorang sendiri merupakan hasil dari proses olah spiritual dari jiwajiwa yang tenang, yaitu berusaha mendekatkan diri kepada Tuhan, dengan cara mengamalkan segala perintah-Nya dan menjauhi segala laranganNya. ${ }^{17}$ Usaha ini harus dilakukan secara konsisten (istiqomah), karena pada hakikatnya segala kebaikan itu mudah untuk dilakukan, yang sulit adalah untuk istiqomah dalam menjalankan.

Konsistensi dalam perbuatan baik adalah modal utama bagi manusia Jawa untuk mengamalkan lapisan-lapisan falsafah hidup Jawa yang terdiri dari tiga bagian. Pertama, adalah lapisan normatif, yaitu kemampuan untuk menjadikan diri sendiri sebagai etika yang mampu memberi petunjuk kepada orang lain tentang bagaimana cara untuk berperilaku baik. Kedua, adalah lapisan manusia sempurna, yaitu kemampuan untuk menyelaraskan jagat besar dan jagat kecil (makrokosmos dan mikrokosmos), antara nafsu yang mengacau harmoni dan konsentrasi keutuhan diri. Pada lapisan kedua ini kata "batin" menjadi kunci. Batin ditunjukkan sebagai tempat manusia untuk meletakkan diri, sumeleh dalam kesejatian dirinya manakala bersatu dengan asal mula hidup, yang sering dibahasakan dengan "roh". Ketiga, lapisan sangkan paraning dumadi, yaitu puncak dari ajaran spiritualitas Jawa. Sangkan paraning dumadi yang secara harfiah berarti "awal dan akhir", artinya manusia hendaknya terus memikirkan dari mana segala sesuatu berasal, dan kemana semuanya itu akan menuju. ${ }^{18}$

Hasil dari kawruh sangkan paraning dumadi ini lantas diimplementasikan dalam kehidupan sehari-hari untuk menciptakan sebuah harmoni. ${ }^{19}$ Ada empat tahap dari kawruh sangkan-paran, yaitu tahap menjadi murid (syarengat), tahap bertobat dan menjalani perintah dengan cinta (tarekat), tahap menemukan kenyataan yang terdalam (hakekat), dan tahap mencapai puncak kesempurnaan pengetahuan (makripat). Tahap keempat ini akan ditemukan apabila sudah dapat menemukan Sang Sumber Pengetahuan, yaitu Tuhan semesta alam. ${ }^{20}$

Lapisan-lapisan filsafat hidup Jawa di atas tidak bisa dilakukan tanpa hati yang bersih. Bersihnya hati seseorang tergantung dari amal dan ibadah yang telah dilakukan selama hidup di dunia. Oleh karena itulah dikatakan bahwa konsistensi dalam melakukan kebaikan menjadi modal utama manusia untuk mengamalkan kawruh sangkan paraning dumadi. Dengan kawruh sangkan paran manusia akan menemukan jati dirinya dan mendapatkan hakikat dari sebuah kehidupan yang akan membawa harmoni. Harmoni sendiri dalam alam pikiran Jawa berarti serasi, selaras, dan seimbang. ${ }^{21}$ Harmoni adalah keselarasan yang menjadi arah hidup alam pikir Jawa. Dalam harmoni ada kesatuan manusia

\footnotetext{
17. Kasnadi, "Nilai Religi: Sebuah Kearifan Lokal dalam Cerita Rakyat Ponorogo", Ibda, Vol. 15, No. 1, 2017 , hlm. 156.

18. Mudji Sutrisno, "Membaca Wajah-Wajah Kebudayaan", dalam Komaruddin Hidayat dan Putut Widjanarko, Reinventing Indonesia: Menemukan Kembali Masa Depan Bangsa (Jakarta: Mizan Pustaka, 2008), hlm. 386.

19. Franz Magnis Suseno, Pijar-Pijar Filsafat: Dari Gatholoco ke Filsafat Perempuan, dari Adam Muller ke Postmodernisme (Yogyakarta: Kanisius, 2005), hlm. 40.

20. Mudji Sutrisno, Op. Cit., hlm. 387.

21. Daldiyono Hardjodisastro dan Wistodiyono Hardjodisastro, Ilmu Slamet: Merangkai Mutiara Filsafat Jawa di Era Moderniasi dan Globalisasi (Jakarta: Bhuana Ilmu Populer, 2010), hlm. 168.
} 
dengan alam semesta, sehingga penguasaan harmoni melalui keseimbangan jiwa akan memunculkan situasi tenang, tertib, damai, dan sejahtera. ${ }^{22}$

Pandangan dunia masyarakat Jawa dengan dibalut ajaran Islam inilah yang diajarkan oleh Bathara Katong agar dimengerti, dihayati, dan diamalkan oleh masyarakat Ponorogo, agar Ponorogo menjadi kota yang penuh harmoni. Maka perubahan nama dari Wengker (wewengkon kan angker) yang memiliki konotasi negatif menjadi Ponorogo bukanlah sesuatu yang begitu saja terjadi. Ada banyak makna filosofis dari perubahan ini, sebagai ikhtiar untuk menjadikan masyarakat Ponorogo sebagai masyarakat yang madani, yaitu masyarakat yang dinamis, penuh kreativitas, dan menjunjung tinggi nilai-nilai peradaban.

\section{Ponorogo Masa Kini}

Catatan kelam Ponorogo di masa lalu hanya tinggal cerita yang dituturkan oleh para orang tua kepada anak-anaknya. Saat ini Ponorogo berkembang menjadi kota yang dinamis dan menjunjung tinggi nilai-nilai peradaban. Ponorogo tumbuh sebagai kota yang religius bahkan mendapat julukan sebagai kota santri. Julukan ini muncul karena banyaknya jumlah santri dan pesantren di kota Ponorogo. Dilansir dari laman Pangkalan Data Pondok Pesantren (PDPP) milik Kementerian Agama Republik Indonesia (Kemenag RI), sampai tahun 2018 terdapat sembilan puluh satu pesantren yang tersebar di kota Ponorogo..$^{23}$

Banyaknya pesantren di Ponorogo menyebabkan gairah dakwah meningkat dari hari ke hari. Intensitas dakwah yang tinggi banyak berdampak pada kehidupan masyarakat Ponorogo, termasuk dalam bidang tradisi, seni, dan budaya. ${ }^{24}$ Kondisi ini kemudian banyak menyadarkan masyarakat
Ponorogo untuk meninggalkan praktik-praktik mistik sisa masa lalu secara bertahap. Proses ini biasanya dilakukan melalui komodifikasi budaya, yaitu dengan memodifikasi budaya yang awalnya identik dengan ritual mistik menjadi budaya yang bersifat profan. Kesenian Reyog Ponorogo menjadi salah satu contoh dari proses komodifikasi budaya ini. ${ }^{25}$

Melihat dinamika masyarakat Ponorogo saat ini, tampaknya cita-cita dari Bathara Katong dan para pendiri yang lain agar masyarakat Ponorogo tumbuh menjadi masyarakat madani perlahan mulai terwujud. Terlepas dari segala kekurangan yang ada, masyarakat Ponorogo terus berkembang menjadi masyarakat yang beradab. Dakwah yang tidak pernah berhenti dari kaum santri senantiasa mengajak masyarakat Ponorogo untuk terus menggali jati dirinya, sehingga Ponorogo yang harmoni bukan sekedar cita-cita hampa, tetapi terwujud dalam kehidupan yang nyata.

\section{PENUTUP}

Kesimpulan dari penelitian ini adalah:

1. Wengker adalah nama sebelum islamisasi yang dilakukan oleh Bathara Katong di Ponoroo. Wengker adalah kerata basa "wewengkon kang angker", yaitu suatu wilayah yang menakutkan. Sebutan ini merujuk kepada kondisi sosiologis masyarakatnya yang terkenal tidak ramah dan kerap melakukan ritual-ritual mistik. Citra negatif Wengker berubah sejak masa persebaran Islam di Jawa abad ke-15 yang dilakukan oleh Bathara Katong. Sebagai manifestasi dari perubahan masyarakat ini, pada tahun 1418 Saka (1496 M) Bathara Katong mengubah nama Wengker menjadi Ponorogo.

22 Carolus Lwangga Tindra Matutino Kinasih, Mistik Ketimuran: Perjumpaan Hinduisme dengan Penghayatan Kebatinan dalam Budaya Jawa (Yogyakarta: Deepublish, 2016), hlm. 110.

23 www.pbsb.ditpdpontren.kemenag.go.id

24 Salah satu contoh adalah perubahan nama dari larung sesaji ke larung risalah, disertai perubahan esensi tradisi. Apabila sebelumnya sesaji yang dilarung ke Telaga Ngebel ditujukan kepada roh-roh nenek moyang, maka dalam larung risalah doa ditujukan kepada Allah Swt, sehingga tumpeng yang dilarung tidak lagi bermakna sesaji tetapi sekedar sebagai simbol tradisi. Maulana Mitanto, Abraham Nurcahyo, "Ritual Larung Sesaji Telaga Ngebel Ponorogo (Studi Historis dan Budaya)", Agastya, Vol. 2, No. 2, 2012, hlm. 47.

25 Asmoro Achmadi, "Pasang Surut Dominasi Islam terhadap Kesenian Reog Ponorogo”, Analisis, Vol. XIII, No. 1, 2013, hlm. 127. 
2. Setidaknya ada tiga versi tentang asal-usul nama Ponorogo. Pertama adalah gabungan dari pramana yang berarti waspada dan raga yang berarti badan. Penamaan Ponorogo dari sudut ini dapat dimaknai sebagai harapan agar masyarakat Ponorogo memiliki fisik yang kuat dengan didukung ketetapan hati, sebagai hasil dari olah batin yang mantap. Kedua adalah gabungan dari pana yang berarti pintar dan raga yang berarti badan. Dari sudut ini penamaan Ponorogo dapat dimaknai sebagai harapan agar masyarakat Ponorogo memiliki fisik yang kuat dengan diimbangi kemampuan intelektual yang baik. Ketiga berkaitan dengan legenda masyarakat setempat yang sarat dengan unsur mistis, yaitu munculnya Ki Prana sebagai penjelmaan Ki Ageng Kutu yang moksa setelah bertarung dengan Bathara Katong. Dari sosok Ki Prana ini kemudian muncul sebutan Pranaraga.

3. Terlepas dari segala perbedaan asal-usul, pemberian nama Ponorogo merupakan ikhtiar dari Bathara Katong dan para pengikutnya untuk mengubah masyarakat Wengker menjadi masyarakat yang lebih beradab. Dari istilah Ponorogo, Bathara Katong seperti hendak meyampaikan bahwa di dalam raga seseorang, tersimpan sebuah rahasia besar yang berada di dalam batinnya. Batin ini jika terus dilatih dengan olah spiritual dalam jiwa yang tenang, maka akan dapat membawa seseorang menemukan jati dirinya dan membawa harmoni dalam kehidupan.

4. Pada masa kini Ponorogo berkembang menjadi kota yang dinamis dan religius bahkan mendapat julukan sebagai kota santri. Julukan ini muncul karena banyaknya jumlah santri dan pesantren di kota Ponorogo. Banyaknya pesantren menyebabkan gairah dakwah meningkat dari hari ke hari, yang berdampak pada kehidupan masyarakat Ponorogo. Kondisi ini kemudian banyak menyadarkan masyarakat Ponorogo untuk meninggalkan praktik-praktik mistik sisa masa lalu. Proses ini biasanya dilakukan melalui komodifikasi budaya, yaitu dengan memodifikasi budaya dari mistik ke profan.

\section{DAFTAR PUSTAKA}

Achmadi, Asmoro, 2013. "Pasang Surut Dominasi Islam terhadap Kesenian Reog Ponorogo", Analisis, Vol. XIII, No. 1, hlm. 111-134.

Allen, Pamela. "Reading Matters: An Examination of Plurality of Meaning in Indonesia Fiction 19801995". Alih bahasa: Soemanto, Bakdi, 2004. Membaca, dan Membaca Lagi: [Re]interpretasi Fiksi Indonesia, 1980-1995. Magelang: Indonesia Tera.

Fauzanafi, Muhammad Zamzam, 2005. Reog Ponorogo: Menari di antara Dominasi dan Keragaman. Yogyakarta: Kepel Press.

Fikriono, Muhaji, 2012. Puncak Makrifat Jawa: Pengembaraan Batin Ki Ageng Suryomentaram. Jakarta: Noura Books.

Hardjodisastro, Daldiyono; Hardjodisastro, Wistodiyono, 2010. Ilmu Slamet: Merangkai Mutiara Filsafat Jawa di Era Moderniasi dan Globalisasi. Jakarta: Bhuana Ilmu Populer.

Hidayati, Nuril, 2014. "Kontestasi Politik Budaya antara Wengker dan Kadiri: Fragmentasi Genealogi Kesenian Jaranan", Prosiding Filsafat Islam: Historisitas dan Aktualisasi (Peran dan Kontribusi Filsafat Islam bagi Bangsa), Vol. 1, hlm. 162-193. 
Kasnadi, 2017. "Nilai Religi: Sebuah Kearifan Lokal dalam Cerita Rakyat Ponorogo", Ibda, Vol. 15, No. 1, hlm. 149-164.

Khoirurrosyidin, 2014. "Dinamika Peran Warok dalam Politik Di Ponorogo", Humanity, Vol. 9, No. 2, hlm. 25-37.

Kinasih, Carolus Lwangga Tindra Matutino, 2016. Mistik Ketimuran: Perjumpaan Hinduisme dengan Penghayatan Kebatinan dalam Budaya Jawa. Yogyakarta: Deepublish.

Liliweri, Alo, 2002. Makna Budaya dalam Komunikasi Antarbudaya. Yogyakarta: LKiS.

Mitanto, Maulana; Nurcahyo, Abraham, 2012. "Ritual Larung Sesaji Telaga Ngebel Ponorogo (Studi Historis dan Budaya)", dalam Agastya, Vol. 2, No. 2, hlm. 36-53.

Muljana, Slamet, 2005. Menuju Puncak Kemegahan (Sejarah Kerajaan Majapahit). Yogyakarta: LKiS.

Nurcahyo, Abraham, 2012. "Ritual Larung Sesaji Telaga Ngebel Ponorogo (Studi Historis dan Budaya)", Agastya, Vol. 2, No. 2, hlm. 36-53.

Perwowijoyo, 1978. Babad Ponorogo. Surabaya: Nirbita

Rahardjo, Supratikno, 2002. Peradaban Jawa: Dinamika Pranata Politik, Agama, dan Ekonomi Jawa Kuno. Depok: Komunitas Bambu.

Ras, J.J., 2014. "Maatschappij en Letterkunde op Java". Alih bahasa: Ikram. Achdiati., 2014. Masyarakat dan Kesustraan di Jawa. Jakarta: Pustaka Obor.

Riyadi, M. Irfan; Mujahidin, Anwar; Tasrif, Muh., 2016. "Conflict and Harmony between Islam and Local Culture in Reyog Ponorogo Art Preservation”, El-Harakah, Vol. 18, No. 2, hlm. 145-162

Rofiq, Ahmad Choirul, 2016. "Patriotisme Masyarakat Ponorogo Menurut Babad Ponorogo", Dialogia, Vol. 14, No. 1, hlm. 135-157.

Santoso, Agus, 2014. Arjunawiwaha. Cianjur: Wiraraja Press.

Semiawan, Conny; Setiawan, Th.I. Immanuel; Yufiarti, 2005. Panorama Filsafat Ilmu: Landasan Perkembangan Ilmu Sepanjang Zaman. Bandung: Teraju.

Sugianto, Alip, 2017. "Pola Nama Desa di Kabupaten Ponorogo pada Era Adipati Raden Batoro Katong (Sebuah Tinjauan Etnolinguistik)”, Humaniora, Vol. 10, Ed. 1, hlm. 34-46.

Suseno, Franz Magnis, 2005. Pijar-Pijar Filsafat: Dari Gatholoco ke Filsafat Perempuan, dari Adam Muller ke Postmodernisme. Yogyakarta: Kanisius.

Sutrisno, Mudji, “Membaca Wajah-Wajah Kebudayaan”. Dalam Komaruddin Hidayat \& Putut Widjanarko, 2008. Reinventing Indonesia: Menemukan Kembali Masa Depan Bangsa. Jakarta: Mizan Pustaka.

Wilson, Ian Douglas, "Reog Ponorogo Spirituality, Sexuality, and Power in a Javanese Performance Tradition", Intersections: Gender and Sexuality in Asia and the Pacific, Issue 2, 1999, http:// intersections.anu.edu.au/issue2/Warok.html.

www.pbsb.ditpdpontren.kemenag.go.id, diakses peada Senin 19 Maret 2018. 
